high level of chronic disability and long-term needs. Predictably, the majority of attenders suffered from schizophrenia, the mental illness most commonly causing severe disability in adulthood, suggesting that resources were appropriately used supporting many such patients in the community. Ravensbourne had a lower proportion of clients with schizophrenia than the other two centres and its recent influx of new attenders may reflect an emphasis on providing a mental health facility for a less chronically disabled population. While many day hospitals seem to serve the psychiatric chronically disabled population for whom day centres were planned, Ravensbourne in some respects seems to be catering for those with short-term needs or having difficulty retaining some of those with long-term needs.

The lack of psychiatric or other support for some people, and, the fact that many lived alone in unsupported accommodation further emphasises the crucial role of the day centres in long-term care and support for this vulnerable group. However, it also casts some doubt on the existence of effective collaboration between psychiatric and social services staff in the management of this group.

A striking finding is the very large population of elderly clients and of clients in their 50s due to become elderly in the next 15 years. It is vital for local services to make long-term plans to provide for this. While Southwark has a model day centre for the elderly demented, there is no specific day centre provision for elderly people with functional mental illnesses. It is important that staffing levels and facilities at day centres are regularly reviewed to consider this, particularly in the light of the additional physical impairments the elderly often suffer from: for example, the two flights of stairs at one of the centres were obviously inappropriate for an ageing population. It may be preferable to provide different, age-appropriate, rather than work-related activities for the elderly. Thirty years ago this group of people would probably have died in mental institutions but now they will need continued support in the community. Further research is needed in order to plan effectively for this elderly isolated and vulnerable group.

\section{Acknowledgements}

Thanks to Jim Birley for suggesting this survey and his comments on an earlier draft. Thanks to Pat Stafford of Southwark Social Services for her support and encouragement in carrying out this study and to the staff of the three day centres for their cooperation. Thanks also to the management committee of Lea day centre which is run as a charity.

\section{References}

Brewin, C. R., Wing, J. K., Mangen, S. P., Brugha, T. S., et al (1988) Needs for care among the long-term mentally ill: a report from the Camberwell High Contact Survey. Psychological Medicine, 18, 457-468.

Creed, F., Black, D. \& ANThony, P. (1989) Day-hospital and community treatment for acute psychiatric illness: a critical appraisal. British Journal of Psychiatry, 154, 300-310.

Herz, M. I., Endicott, J., SPitzer, R. L. \& Mesnikoff, A. (1971) Day patient versus in-patient hospitalisation: a controlled study. American Journal of Psychiatry, 127, 1371-1381.

MCGRATH, G. \& TANTUM, D. (1987) Long stay patients in a psychiatric day hospital: a case note review. British Journal of Psychiatry, 150, 836-841.

PRYCE, I. G. (1982) An expanding 'stage army' of long-stay psychiatric day patients. British Journal of Psychiatry. 142, 595-601.

\title{
Thirty years on: The Glenside Hospital Surveys 1960-1990
}

\author{
RebecCa J. Eastley, Registrar in Psychiatry, Glenside Hospital, Blackberry Hill, \\ Stapleton, Bristol BS16 1DD; and PHILIP LuCAS, Registrar in Psychiatry, \\ The Maudsley Hospital, London SE5 8AZ
}

Since 1960 , there has been a five yearly review of the population resident for more than three months at Glenside Hospital, Bristol (Cooper \& Early, 1961; Early \& Magnus, 1966; Early \& Nicholas, 1971; 1977; 1981; Ford et al, 1987). These surveys have particularly focused on the accommodation and employment needs of the in-patients, but have also documented the nature of the changes that have occurred in the mental hospital over the last 30 years. The results of the seventh quinquennial survey are reported. 


\section{The study}

This survey was conducted using the method first employed in 1960, and utilised in all the subsequent surveys. A schedule of 34 items was completed for all patients resident for more than three months on 1 January 1990 . The information was obtained from the nursing staff, case-notes and hospital records.

\section{Findings and comparison with other surveys \\ Hospital population}

On 1 January 1990 there were 294 patients (148 male, 149 female) who had been resident for more than three months at Glenside Hospital. Over the last 30 years the population has fallen by 718 patients $(72 \%)$, an average decline in population of $2.4 \%$ per year. Much of the decline in population is accounted for by a fall in patients resident for greater than five years, both in absolute numbers and as a percentage of the total population.

The population resident for more than five years has fallen by $29 \%$ since 1985 . Within this group, the number of patients with a diagnosis of schizophrenia has fallen from 168 in 1985 , to 103 in 1990 , a $39 \%$ fall. Only $65 \%$ patients resident for more than five years have a diagnosis of schizophrenia, compared with $76 \%$ in 1985 . Much of this change is due to the death of many of the older "long-stay" patients. Fortyseven patients who had been resident for more than five years at the time of the 1985 survey have since died. Thirty-nine of these patients were over 65 years old, and 31 had a diagnosis of schizophrenia. However, many "long-stay" patients are now resettled in the community, and fewer patients with functional illness are becoming "long-stay". The other main change in diagnostic category since 1985 has been for senile dementia. In $1985,5 \%$ of the population resident for more than five years had a diagnosis of senile dementia, compared with $10 \%$ in 1990. Although the total numbers of patients with senile dementia have changed little $(65,1985 ; 68$, 1990), their longevity is increasing. In 1990, 16 patients with senile dementia had been resident for more than five years and four for more than ten years.

The population resident two to five years has also fallen, but less steeply in recent years. Since 1960 this group has decreased by $61 \%$, but only by $23 \%$ since 1975. In this group there has been a small change in the numbers of patients with schizophrenia or senile dementia. In 1990 there were 24 patients with a diagnosis of senile dementia, and 17 with a diagnosis of schizophrenia. In 1985, 30 patients had senile dementia, 13 schizophrenia. There were no other significant changes in diagnostic categories.
Although the population resident three months to two years declined by $42 \%$ over the period 1960 to 1975 , there has been no significant change in the numbers since $1975(86,1975 ; 87,1990)$. The only significant diagnostic change since 1985 has been for affective disorder. In 1985, 23 patients were diagnosed as suffering from affective disorder, compared with 11 in 1990. As suggested by the authors of the 1985 survey, the increase in the numbers of patients with affective disorder in 1985 could be representative of a change in diagnostic habits, or a transient increase in prevalence. As in 1985, the commonest single diagnosis was senile dementia, 28 patients, followed by schizophrenia, 26 patients $(1985,27$ senile dementia, 22 schizophrenia). Looking at this group in total, only $15 \%$ enjoyed good social participation, and only $40 \%$ presented no anti-social behaviour. These patients seem to represent a group for which a period of medium term hospital stay is required.

The population has consistently aged since 1960 , so that in $1990,51 \%$ men and $70 \%$ women were over 65 years compared with $22 \%$ men and $43 \%$ women in 1960 . Only $16 \%$ of the population in 1990 was under 45 years old, but $37 \%$ were over 75 years old.

There has been a significant increase in the number of detained patients since 1985. However, this is largely attributable to the opening of the Fromeside Clinic, a Regional Secure Unit, in 1988. Of the 36 detained patients, 17 were in-patients at Fromeside.

As in 1985 , over $80 \%$ of the resident population was unemployed. Unemployment remains the norm for psychiatric in-patients. Only four patients were employed outside the hospital, and only 17 attended the Integrated Rehabilitation Workshops. The implication is that industrial therapy is increasingly a day patient activity.

Thirty-six patients worked in hospital departments or performed ward chores. This left a massive 237 patients with no work and a variable degree of occupational therapy on the wards.

The paucity of outside contact for psychiatric inpatients continues. A staggering $73 \%$ of patients never went out, and were rarely or never visited. Of 158 patients resident for more than five years, only 12 visited friends or relatives regularly. Equally disturbing is the fact that only 14 of 87 patients resident between three months and two years went out regularly. As the length of hospital stay increases, the amount of outside contact decreases. Women are no more likely to go out than men, but are marginally visited more. This could be related to several factors. More men than women show moderate to severe anti-social behaviour, although not dramatically so ( $55 \%$ men, $47 \%$ women). Seventy-one per cent of men were single, compared with only $34 \%$ women. Thirty-six per cent of women were widowed, but only $4 \%$ men. Some women patients may have children who keep in contact. Additionally, 57\% women 
enjoy fair to good social participation, but only $35 \%$ of the men. These findings support Hunt's statement (1985) that "the remaining long-stay patients include those with the most intractable handicaps and the fewest remaining contacts with the community". The "outside" must seem like an alien and friendless place.

The proportion of patients requiring either no nursing care or minimal supervision has steadily decreased from $47 \%$ in 1960 to $18 \%$ in 1990 . Of the 146 patients with a diagnosis of schizophrenia, 94 were considered to require routine psychiatric nursing, 2 general nursing, and 19 necessitated "special attention". Only 26 needed minimal supervision, and 5 no nursing care or supervision.

The level of dependency has increased. Forty-five patients were permanently chairfast or confined to bed, and 41 patients were ambulant only part of the day. Thirty-two of the permanently immobile patients had senile dementia.

There appears to have been some change in the expectations of care in the community since 1985 . Forty-one per cent were felt not to require hospital accommodation, compared with $28 \%$ in 1985 , and yet this population is by no means a less disabled group than five years ago. Of 100 patients who were thought to require supervised accommodation, 69 had a diagnosis of schizophrenia, 9 personality disorder, and 8 affective psychosis. Forty-two of these patients were over 65 years old, including 13 over 75 , and 5 over 85 . This apparent change in accommodation needs may be more indicative of a change in attitude towards deinstitutionalisation. Many of these patients could enjoy a better quality of life in the community, but discharge without appropriate provision of locally based services would be sentencing them to an isolated, impoverished existence. One hundred and thirty-seven patients were felt to require psychiatric hospital care; 67 had a diagnosis of schizophrenia; 38 senile dementia, and 13 affective psychosis. Fifty per cent of these patients were over 75 years old.

Of 19 patients thought to be suitable for unsupervised accommodation, 11 had affective psychosis, 4 schizophrenia, 3 neurotic disorder, and 1 personality disorder. All but one patient were under 65 years old.

Using the data obtained from the 1985 survey, it was predicted that in 1995 the population resident for more than three months would number 294 . The same method was used to predict the estimated population for 1990 , and the figure was 330 . The actual number of patients resident at Glenside Hospital in 1990 was 294. However, ten patients were resident at Causeway House, a rehabilitation nursing home, and 21 in community homes. This accommodation is provided by the Frenchay Mental Health Trust and is staffed to similar levels as the hospital wards. If these patients are included, the total population becomes 325 . This endorses the estimated fall in population of approximately $2 \%$ per annum.

\section{Comment}

The Glenside population is ageing, and becoming increasingly handicapped. This is the experience of other psychiatric hospitals, and is a legacy of the successful discharge of the least impaired patients over the last 30 years. The population continues to reduce, but the rate is decelerating. This trend will not be reversed without better provision of sheltered accommodation, and a true community service incorporating the full range of facilities necessary for psychiatric patients to achieve their full potential.

There is a sizeable proportion of patients who still require some of the facilities and environmental aspects afforded by the "traditional" mental hospital, as yet not fully available in the community. Their quality of life should not be allowed to deteriorate as the mental hospital is run down, and resources are withdrawn.

\section{Acknowledgements}

We would like to thank Dr M. Nicholas for his advice and encouragement while preparing this paper, and $\mathrm{Mr}$ A. Hayward for help with data analysis and the statistics. We would also like to thank all the nursing staff who helped collect the data.

\section{References}

COOPER, A. B. \& EARLY, D. F. (1961) Evolution in the mental hospital: review of a hospital population. British Medical Journal, i, 1600-1603.

Early, D. F. \& Magnus, R. V. (1966) Population trends in a mental hospital. British Journal of Psychiatry, 112, $595-601$.

— \& NiChOlaS, M. (1971) The developing scene: ten year review of a psychiatric hospital population. British Medical Journal, ii, 793-795.

— \& - (1977) "Dissolution of the mental hospital": fifteen years on. British Journal of Psychiatry, 130, $117-122$.

- \& (1981) Two decades of change: Glenside Hospital population surveys 1960-1980. British Medical Journal, 282, 1446-1449.

Ford, M., GodDARD, C., \& LANDSELl-Welfare, R. (1987) The dismantling of the mental hospital? Glenside Hospital Surveys 1960-1985. British Journal of Psychiatry. 151, 479-485.

HUNT, L. B. (1985) Implementation of policies for community care: the DHSS contribution. Health Trends, 17, 4-6. 